\title{
Don Quijote y Roque Guinart frente al estilo de vida de los poderosos
}

\author{
ISABEL M. ROGER*
}

\begin{abstract}
Resumen
La Segunda parte apócrifa del Quijote modificó muchos de los propósitos de Cervantes. Varió el destino de su héroe. Sostuvo que la publicación tuvo lugar en Barcelona como don Quijote observa en la visita a una imprenta. Dio protagonismo a un núcleo urbano como en la novela picaresca. Ahora bien, no cambió su actitud frente a los poderosos que actuaban en la línea de la estulticia de Erasmo. Seguramente reafirmó su planteamiento de la Edad Dorada con la presencia de Roque Guinart, el único personaje histórico, que aparece en la novela. Este trabajo analiza cómo se comportan los poderosos frente a don Quijote y cómo coincide su actuación con la de Roque Guinart.
\end{abstract}

Palabras Clave: Don Quijote; Barcelona; Roque Guinart; el Quijote apócrifo; Erasmo; Caballero del Verde Gabán; ociosidad de los poderosos; utopía de la Edad Dorada; historia y poesía.

Title: Don Quixote and Roque Guinart against the way of life of the influential people

\begin{abstract}
The apocryphal Second part of don Quixote altered many of the purposes of Cervantes. He changed the destination of his hero. As observed by don Quixote when visiting a printinghouse, its publication took place in Barcelona. The author gave prominence to a town as in picaresque novels. However, he did not modify his attitude towards the behaviour of the influential people, in keeping with Erasmus' concept of stupidity. Surely, Cervantes reaffirmed his approach to the golden age through the presence of Roque Guinart, the only historical character who appears in the novel. This paper examines how the influential people behave in front of don Quixote, and how his performance is similar to that of Roque Guinart.
\end{abstract}

Key Words: Don Quixote; Barcelona; Roque Guinart; the Apocryphal Quixote; Erasmus; the Gentleman in Green; Influential People's Idleness; Golden Age utopy; History and Poetry.

* Institut Mercè Rodoreda, L'Hospitalet de Llobregat, Barcelona.iroger@xtec.cat 
Próximo a su fin novelesco, es cuando en el Quijote se hace más patente la afinidad del ideario del protagonista con el único personaje histórico que surge en el relato, Roque Guinart, frente al de los poderosos que afloran en esta Segunda parte, como el Caballero del Verde Gabán y los duques; la rendición de cuentas, a través del protagonista, con el autor apócrifo de la Segunda parte y la aparición, como en la novela picaresca, de un espacio urbano. La combinación de estos tres elementos contribuye a diluir la tenue frontera entre ficción y realidad. Para analizar este proceso, se estudiará la función de cada uno de estos que además están presentados bajo el cuño inconfundible del estilo cervantino en cuya base reside el mensaje de la elocuencia y la ironía de la moria erasmiana. Cervantes crea de forma novedosa una demoledora crítica social al panorama que envuelve la vida del caballero manchego más famoso de la literatura.

\section{BARCELONA Y LA APARICIÓN DE LA SEGUNDA PARTE APÓCRIFA}

Barcelona es el último enclave y el único urbano, dentro de la geografía caballeresca de don Quijote, que además presenciará su derrota final, tras la cual muere si no física, sí psíquicamente: 'como si hablara dentro de una tumba, con voz debilitada y enferma' (II, 64, 1047) ${ }^{1}$. Ahora defiende, como siempre, la belleza de su amada, pero pide a su contrincante que le atraviese con la lanza, pues perdida la honra su ideal flaquea. ¿Qué es lo que ha propiciado que este hidalgo manchego, cuya función de caballero andante ha mantenido obstinadamente, decida desaparecer tras la aparición de la subrepticia continuación de sus aventuras bajo la pluma del 'escritor fingido y tordesillesco' (II, 74, 1105)?

Esta ciudad que tanto admiró Cervantes en el Quijote y en su novela ejemplar, Las dos doncellas, ha asistido también a la publicación de la apócrifa Segunda parte: 'que contaba con una falsa aprobación y un falso lugar de impresión, ya que este fue en realidad Barcelona' (Maldonado 2004: 64, Blasco 2006: 15) ${ }^{2}$, pero permite que acoja la estancia de don Quijote en la ciudad condal (II, 60-66) con diversas funciones. La primera, y más relevante, cambiar el rumbo prometido a su héroe para aclarar de una vez por todas quién es el verdadero héroe que pretende acabar con toda esa inventiva de los libros de caballerías. Función que queda referida en el encuentro con dos caballeros que en una venta leen la falsa Segunda parte y quisieran aclarar

1. Cervantes (2012). Todas las citas del Quijote son de esta edición.

2. Tanto Maldonado en Quién es quién en el Quijote y en el Quijote de Avellaneda como Rico, en sus anotaciones al Quijote, en Santillana en 2012, establecen la edición de Avellaneda en Barcelona. Otros editores la cuestionan: Florencio Sevilla editor del Quijote en Alianza en 2011. El estudio de Javier Blasco deja menos resquicio a cualquier duda sobre la cuestión. 
qué hay en ella de cierto (II, 59), pues no comprenden a don Quijote desenamorado de doña Dulcinea. Será mucho después cuando abandonada la ciudad condal, en un mesón, encuentre a un personaje, Álvaro Tarfe, de la Segunda parte apócrifa que se acreditará ante la autoridad quiénes son los verdaderos don Quijote y Sancho Panza (II, 72). Así pues, antes y después de la estancia en Barcelona es cuando queda claro quién es el verdadero don Quijote y cuáles son sus hazañas. La segunda función, de la ciudad condal dentro de la Segunda parte, es hacer coincidir su estancia, con la visita a una imprenta, con las disquisiciones intelectuales de don Quijote que era un buen lector de libros de ficción, y además se sabe -desde el inicio de esta Segunda parte- uno de sus protagonistas más famosos (II, 3) pero ahora revela sus conocimientos - entre otros- en lengua toscana o italiana (II, 62). Don Quijote es consciente de que es en esta ciudad donde ha visto la luz la Segunda parte apócrifa (II, 62). Coincidencia que le sirve a Cervantes para devolver, a través del personaje, los improperios del apócrifo Avellaneda le había dirigido: 'su San Martín se le llegará como a cada puerco que las historias fingidas tanto tienen de buenas y deleitables ... cuanto son más verdaderas' (II, 62, 1033). Relaciona, además, los dos conceptos establecidos y discutidos sobre poesía e historia al principio de la Segunda parte:

...el poeta puede contar o cantar las cosas, no como fueron, sino como debían ser, y el historiador las ha de escribir, no como debían ser, sino como fueron, sin añadir ni quitar a la verdad cosa alguna (II, 3, 569).

Si la concepción poética había podido ser la base de la Primera parte, ahora está claro que ambos conceptos se enlazan al saberse protagonista de un libro que cuenta su historia (II, 2). Más adelante veremos cómo se logra diluir la separación entre ambos conceptos.

La actuación de don Quijote no variará en casa de Antonio Moreno donde, como en el palacio de los duques, será utilizado como invitado con el cual se puede pasar un rato divertido. Finalmente, su derrota lo devolverá definitivamente a su aldea, como declara Sancho en cuanto la divise: 'que si viene vencido de los brazos ajenos, viene vencedor de sí mismo' (II, 72, 1093). Declaración que ha utilizado la crítica para forjar una imagen de Cervantes más próxima al humanista cristiano en la línea de Erasmo (Castro El pensamiento de Cervantes 1972: 272; Allen 1997: 31; Canavaggio 1987: 274), que al autor de un héroe mitificado e idealizado que proponía el sueño romántico, y que pervivió hasta bien entrado el siglo XX (Close).

Si Barcelona es el entorno que pone cierre al ideal caballeresco de don Quijote, requiere de un análisis más acorde con los ideales que ha propuesto el protagonista a través de su andadura. Además la aparición, en sus proximidades, de Roque Guinart, único personaje histórico en la obra, plantea que se contraste su comportamiento, más parecido al de un forajido y un personaje proscrito, con el entorno social de las tres viviendas en las que don Quijote se hospeda. En su momento, Américo Castro ('Cómo veo ahora el Quijote' 
1971: 81) señaló el comportamiento tan poco ético de los personajes poderosos o de noble linaje, por lo tanto se cotejará en qué difieren estos tres grupos de personajes poderosos y por qué se exalta la figura de un bandolero como Roque Guinart cuya actitud -como la del héroe- propone un ideario muy diferente al de los poderosos, aunque solapado entre la parodia de los libros de caballerías, la ironía cervantina y la concepción del autor sobre poesía e historia. Propuesta que además deja entrever de nuevo el concepto de la Edad Dorada apuntada en la Primera parte $(\mathrm{I}, 11)$ como una teoría, que tiene ahora una visión más próxima a la realidad. También es peculiar la presencia de un núcleo urbano más propio de la novela picaresca y que tanto ha rehuido el hidalgo manchego a lo largo de sus aventuras.

Este repertorio de situaciones se da en la Segunda parte con la intervención del sosegado labrador, don Diego de Miranda y el ocioso Duque, así como la actitud relajada de los personajes mejor situados socialmente de la mansión de Antonio Moreno, amigo de Roque Guinart, en el entorno urbano. Estas situaciones persiguen un mismo objetivo, dejar en evidencia la actuación de este sector de la sociedad. Rey Hazas también ha estudiado, en la introducción de la edición del Quijote de Alianza, una interpretación similar al analizar el comportamiento de los presentes en una venta (I, 45), castillo encantado para don Quijote, mientras discuten que si es bacía o yelmo ante los ojos atónitos del barbero que se ha sentido saqueado por don Quijote y Sancho. Lo más relevante es que estos personajes son ficticios mientras que Roque Guinart es el único personaje histórico identificable en el espacio escénico que lo sitúa Cervantes, aunque ya no ejerciera de bandolero -si queremos ser fieles a las pistas cronológicas que nos ha dado en esta Segunda parte con la carta de Sancho a su esposa (II, 36), fechada el 20 julio de 1614- sino que vivía muy alejado de sus antiguas andanzas, indultado en Nápoles desde 1611.

De la Primera a la Segunda parte hay cambios significativos: no es la quinta parte, siguiendo con las divisiones que había hecho en la Primera su autor, y así también el título de la obra se ha modificado: el ingenioso hidalgo ahora es un caballero. Estas modificaciones vienen propiciadas por la aparición de la apócrifa Segunda parte que parece ser un cúmulo de falsedades: su autor se esconde bajo un pseudónimo, tampoco su impresor es Felipe Roberto ${ }^{3}$ y además, Cervantes afirma que no es de Tordesillas, sino aragonés. Ahora bien, Cervantes introduce en esta Segunda parte una novedad: los protagonistas se saben personajes de una obra sobre sus aventuras que se ha publicado y ha tenido éxito. Cervantes crea un tiempo interno dentro de su propia obra en el que podrá cuestionar el devenir de los hechos o introducir lectores de esa Segunda parte apócrifa (II, 59) o alguno de sus personajes como Álvaro Tarfe (II, 72) para dejar claro quién es el verdadero héroe. Este nuevo tratamiento le permitirá diluir los límites entre poesía e historia. Cómo si no, se puede entender que un personaje ficticio sea

3. El estudio de Blasco (2006: 15) analiza cómo Francisco Vindel llegó a la conclusión que fue Sebastián Cormellas y no Felipe Roberto su impresor. 
introducido en una historia verdadera. El prólogo de esta Segunda parte está presidido no tanto por los efectos de la aparición de esas aventuras espurias, sino más bien por los vituperios que le dirige, el autor apócrifo, a Cervantes: su vejez, su manquedad o que le tilde de envidioso. El alcalaíno responde a todo ello con discreción. Tampoco los dos ejemplos del prólogo sobre dos locos tienen desperdicio, uno que hinchaba a un perro con un canuto, para concluir que no es poco trabajo hacerlo o escribir un libro, o aquel otro que golpeaba con una losa de mármol al perro descuidado que con él topaba hasta que un amo lo escarmentó. Son ejemplos que Cervantes pretende que el autor apócrifo entienda que no es posible proseguir con la continuación del héroe manchego. No es casual que Cervantes se haya amparado en dos locos para enmendar la actitud del autor apócrifo. Un loco que realiza una acción sorprendente equiparada a la labor de escribir un libro, u otro que actuaba inoportunamente hasta que recibió el castigo a su atrevimiento. ¿Estaría indicando cómo la locura o la estulticia de corte erasmiano no han sido interpretadas como su autor esperaba? Este autor espurio no ha sabido interpretar ni la finalidad primera de la obra: acabar con esa inventiva de los libros de caballerías, ni con la personalidad y el humanismo del protagonista, como declaran los dos lectores que en la venta discuten sobre la autenticidad de este 'nuevo don Quijote' (II, 59). En definitiva, el apócrifo don Quijote es un loco cuyas características se han escapado del papel que pretendía darle Cervantes.

\section{EL ENTORNO IDEOLÓGICO DE LOS PODEROSOS: EL CABALLERO DEL VERDE GABÁN Y LA MORIA ERASMIANA}

El caso del Caballero del Verde Gabán ha despertado diferentes visiones, desde Marcel Bataillon o Rafael Lapesa, que ven en él un personaje 'sencillo, equilibrado y libre de ambición' ('Góngora y Cervantes' 1971: 230) en pocas palabras el ejemplo de la aurea mediocritas que tanto se había difundido en el Renacimiento. Américo Castro añadió unas notas más críticas a su 'modo de vida sin riesgo ni esfuerzo, ni físico ni intelectual' ('Cómo veo ahora el Quijote' 1971: 93). También Márquez Villanueva ha insistido en el silencio que se respira en la residencia del manchego que acaba poniendo nervioso al protagonista (II, 18). Si se compara el tipo de vida, que lleva este rico labrador con el de don Quijote, es muy similar a la del héroe antes de decidirse a ser caballero andante: deben de rondar la misma edad, la caza es su ocupación y la lectura, también, pero en el caso del Caballero del Verde Gabán no se encuentra, entre los documentos de su biblioteca, ningún ejemplar de los de caballerías, por ello desconoce la reciente publicación de las aventuras del hidalgo manchego. Igualmente, le sorprende y le asusta la actitud de don Quijote cuando se enfrenta a unos leones. Aventura que le valdrá un nuevo sobrenombre: Caballero de los leones, los cuales hartos de tanto trasiego durante un largo viaje, la única respuesta que dan a su osadía es darle la espalda. 
La descripción de la casa del rico labriego corresponde a la de un hombre de su condición, no parece diferir mucho de la de Alonso Quijano. Incluso el ilustrador, que más famosas ha hecho las aventuras de don Quijote, Gustave Doré (1832-1883), ha mostrado, con fidelidad al texto, el pasaje: una entrada amplia en la que aparecen sus armas, aunque toscas, su bodega en el patio, su cueva en el portal y un cúmulo de tinajas del Toboso que le sirvieron a don Quijote para evocar a su amada con los versos del célebre soneto X de Garcilaso de la Vega. Así como el hijo, Lorenzo de Miranda, y la esposa del caballero del Verde Gabán, que salen a darles una cordial bienvenida. En la ilustración de Doré, el caballero del Verde Gabán permanece en la parte derecha de la composición de espaldas al espectador, y un poco más avanzados Sancho y don Quijote, el primero también de espaldas y el hidalgo algo más ladeado -quizás profiriendo esos versos que don Lorenzo escucha sorprendido- que se aproximan a la mansión, cuando lo habitual sería que el dueño guiase a sus invitados. Lo más sorprendente de este personaje, que a todas luces parece la antítesis de don Quijote, es el color verde de su atuendo. No parece que tenga nada que ver con el homónimo Diego de Miranda que estuvo implicado en los desafortunados sucesos del barrio del Rastro de los Carneros en Valladolid cuando murió, en la vivienda del escritor, Gaspar de Ezpeleta.

Este labrador que siempre pone una cierta distancia ante la acción -como pone de relieve Doré- es el personaje más próximo a los ideales del Renacimiento, pero es también el paradigma más cercano a la propuesta de Erasmo: 'el sabio se distingue precisamente del estulto en que aquél se gobierna por la razón y este por las pasiones'4. Principio que en estos dos personajes acaba cruzándose, pues si don Diego parece el más cuerdo de los dos, será después don Quijote quien haga los razonamientos más lúcidos sobre la educación de los hijos. Antonio Vilanova estudió la influencia del humanista holandés en el Quijote, sobre todo en torno a las dos figuras protagonistas de la obra, pero ahora se hace necesario contrastar el comportamiento de otros personajes que también muestran características de la estulticia erasmiana. Esta perspectiva erasmista crea, en éste y otros pasajes del Quijote, la sensación de que los seres, los objetos y las situaciones son polivalentes.

El color verde del atuendo de este caballero no impide que Sancho lo considere un santo, cuando explique su vida. Capítulos después, también la duquesa estará enfundada en ese mismo color, ella y las guarniciones de su carroza (II, 30), por lo tanto habría que preguntarse qué significado guarda este color, porque, también, las medias de don Quijote, en el palacio de los duques que lamentará se le hayan estropeado (II, 44), son de ese mismo color, así como la cinta de la contrahecha celada que se prepara en su primera salida (I, 2). Con todo, el verde parece un color desafortunado en la obra, pues cuando

4. Erasmo de Rotterdam (1976: 59). Se trata de observar las similitudes irónicas que Erasmo y Cervantes hacen sobre la estulticia y la actuación poco racional de algunos personajes en el Quijote. 
Sancho transmite a don Quijote las primeras noticias de la publicación de sus aventuras, 'Dicen los caballeros que no querrían que los hidalgos se opusieran a ellos, especialmente aquellos ... que dan humo a los zapatos y toman los puntos de las medias negras con seda verde' (II, 2, 43), por lo tanto aquellos que pretenden igualarse, sin merecerlo, a su dignidad. No será el único reproche de este tipo que recibe don Quijote (II, 6), pero aquí la aparición del verde (y no otro color poco oportuno para reparar una media negra) da qué pensar sobre su fatídica presencia en su portador. La estulticia en la obra de Erasmo ya había advertido que se 'yerra no solo [en] el sentido, sino también [en] el juicio de la razón [aquel que] nacido en ínfima cuna, ... se figurase ser el rey Creso de Lida' (1976: 74). Cuando escucha don Quijote esta alusión de Sancho, él no se da por aludido porque va siempre bien vestido (II, 2), pero después se quejará del suceso desafortunado de no poder remendar su media verde en el palacio de los duques. También su respuesta sobre los linajes a su sobrina será una evasiva: 'pero por no mezclar [los linajes de] lo divino con lo humano, no las digo' (II, 6, 591). En todo caso es curioso que los personajes menos letrados, como Sancho y su sobrina, sean precisamente los que le llaman la atención sobre haber intentado aparentar lo que no era, porque por origen no podía ser un caballero. Otros, como los duques, basarán su crítica en la burla. Con todo es un intento de presentar - a través de un loco- la osadía de la moria erasmiana en un personaje -como don Quijoteque es, a veces, más razonable que sus burladores.

Don Quijote parece todavía seducido por sus principios y sus ideales que señorean en sus acciones valientes y en sus atrevidas empresas, pero es verde la camiseta de don Quijote cuando le encuentran descansando en su casa el Cura y el Barbero al inicio de la Segunda parte. De terciopelo verde van las doncellas que acompañan el séquito de Quiteria en su boda con el rico Camacho, así como ella misma. De verde damasco se presenta una joven disfrazada de mancebo, ante Roque Guinart y don Quijote, que con esta apariencia ha defendido su honor que creía traicionado. Por ende, el verde es un color que prolifera en la obra más de lo que inicialmente parece. Tiene connotaciones jocosas si se reparan las medias negras con seda verde, pero en situaciones solemnes como una boda el verde también aparece. Aunque es una boda que después resultará un engaño. ¿Es posible que su aparición en tantas y diversas situaciones tenga que ver con el libro verde que registraba con rigor los orígenes de limpieza de sangre de toda la población, pero en especial de la nobleza, según documenta Elliott (1979: 239). Sin embargo, la no existencia de ninguna relación directa, solo permite detallarla como el color que asedia a todos los personajes, en especial a los nobles o los que lo pretenden aparentar que, en definitiva, eran los que estaban más sujetos a ese tipo de inspecciones. Pudiera tratarse de un guiño más de la fina ironía cervantina.

Pero volvamos a don Diego, cuando ambos personajes se encuentran, don Quijote ya no actúa con la precipitada conducta caballeresca de otros episodios. Don Quijote le ofrece, amablemente, compartir el camino. Ambos quedan sorprendidos por sus apariencias, pero el protagonista, demasiado inmerso en sus 
principios de caballero andante, no repara más en ello. Diego de Miranda es consciente de que algo no funciona en este hombre que, sin embargo, parece cuerdo cuando razona sobre otras cuestiones como el futuro de su hijo que quiere proseguir estudios de poesía. En todo caso los dos personajes, en su corta amistad, departen y conviven como si se conocieran desde antaño y, en cierta medida, llegan a intercambiar sus papeles. La locura y la actitud de la moria erasmiana en ambos permiten observar su conducta desde perspectivas diferentes.

Cuando don Quijote se encuentra al hidalgo del Verde Gabán, acaba de vivir el primer enfrentamiento del que sale victorioso con el Caballero de los Espejos que resulta ser el bachiller Sansón Carrasco que pretendía alejarlo de su propósito de vivir como un caballero, pero que además finge haberse enfrentado, con anterioridad, a otro caballero con su mismo nombre. Esta alusión desconocida para el lector -en el texto cervantino- ha hecho sospechar a la crítica que podría, Sansón Carrasco, referirse al don Quijote apócrifo (Gómez Canseco 2006: 46). Sin embargo, el lector es consciente, como lo serán amo y escudero, de la similitud con sus vecinos que don Quijote atribuye a obra de encantadores. La pericia narrativa de Cervantes le permite jugar con la imaginación del lector y la de los propios personajes creando visiones polivalentes: Sansón Carrasco o Caballero de los Espejos cuya duplicidad lleva implícita en su propio nombre o Caballero del Bosque (Gómez Canseco 2006: 46) que además tiene una amada a imagen y semejanza de don Quijote, Casildea de Vandalia. El derrotado caballero y su desenmascarado escudero discernirán sobre quién es el más loco, el que lo aparenta o el que lo es. El caballero de los Espejos un poco mohíno le contesta: 'el que lo es por fuerza lo será siempre, y el que lo es de grado lo dejará de ser cuando quiera' (II, $15,134)$. Y así sucederá en la obra, cuando don Quijote se sienta derrotado y acabado su ideal, su único propósito será regresar para morir en su propio lecho y, además, cuerdo.

La tradición literaria guarda innumerables locuras como la momentánea de Ulises para eludir ir a la guerra o la vesania de Orlando por traición amorosa, pero quizás habría que preguntarse por qué los personajes que rodean a don Quijote buscan soluciones para remediar su locura tan poco racionales como disfrazarse y ponerse a su misma altura. Actitud que recuerda el planteamiento de Erasmo que exponía que los hombres debían a la 'estulticia ilustres deleites en la vida y, sobre todo, el supremo de disfrutar de la insensatez ajena' (1976: 55). En todo caso, llama la atención que el bachiller Sansón Carrasco, que debe de haber estudiado teología en Salamanca, esté al corriente de las aventuras del hidalgo, y en cambio, don Lorenzo de Miranda no tenga noticia alguna, aunque también haya estado en Salamanca durante seis años aprendiendo lenguas latina y griega. En el encuentro fortuito con el rico hidalgo, este no toma la actitud de burla que otros tomaron, y más bien quiere evitar el contacto para impedir que su yegua alborote a Rocinante (II, 16). Esta actitud podría hacer suponer que se trata de un personaje discreto, pero su atuendo lo desmiente, pues el narrador así lo aludirá como 'el de lo verde' durante todo el pasaje. 
Su desconocimiento de las aventuras del hidalgo manchego le impide caer en las trampas y burlas que otros idearon o idearán.

Dentro de la estancia hogareña, sin embargo el Caballero del Verde Gabán queda anulado. Algo parecido a lo que debió de sucederle a Alonso Quijano en su aldea. Ya no departirá más con el caballero manchego y será su hijo, don Lorenzo, quien diagnostique a don Quijote: 'él es un entreverado loco lleno de lúcidos intervalos' (II, 18, 684). Diagnóstico que nunca podrá, con sus etiquetas, superar la crítica cervantina. Si el Caballero del Verde Gabán debiera sentirse a sus anchas y en pleno dominio de su hogar, queda reducido al papel del anfitrión que ha anunciado antes que la comida que ofrece es: 'limpia, abundante y sabrosa' (II, 18, 684). En todo caso lo que maravilla a don Quijote es el 'silencio ... que semejaba un monasterio de cartujos' (II, 18, 684). Cuando don Quijote iba camino del entierro de Grisóstomo, uno de los estudiantes le compara la estrechez de la vida de los caballeros andantes con la de los frailes cartujos. Don Quijote le replica que es más 'trabajos[a], aporreada, hambrienta, sedienta y miserable' $(\mathrm{I}, 13,112)$ la del caballero andante, mientras que los frailes cartujos 'en sosegada paz y reposo están rogando a Dios [que] favorezca a los que poco pueden' (I, 13, 112). Es esa fina ironía que fluye en el discurso cervantino y genera lecturas múltiples para interpretar las diferencias entre cartujos y caballeros andantes. Por consiguiente, intercala en pasajes distintos qué interpreta el héroe entre una y otra ocupación que tienen la misma finalidad: atender a los menesterosos, pero con actitudes opuestas: unos con la acción, los otros con la oración. La falta de acción será una actitud que también despertará su desacuerdo con los poderosos.

En casa de Diego de Miranda, se ha agotado demasiado deprisa la conversación entre los dos personajes que parecían que tenían una condición social similar y, después de cuatro jornadas regaladas, don Quijote decide pedir licencia para irse porque los caballeros se debían a sus aventuras y no al ocio y al regalo (II, 18), y seguramente es donde estriba la gran diferencia entre estos dos personajes que de extracción social parecida se alejan, frontalmente, en su actitud vital. En este extremo que tanto los separa es donde Cervantes realiza la crítica a un grupo social como el de los ricos hidalgos -mayoritariamente cristianos viejos (quizás por eso la comida que ofrece don Diego de Miranda es 'limpia')- que pasan sus vidas en el más triste de los anonimatos pero que no contribuyen con su actitud, de no querer trabajar con las manos, al desarrollo de un país que dejó su economía reducida al ostracismo por no haber puesto en funcionamiento la industria que demandaba cubrir las necesidades del Nuevo Mundo. Don Quijote advierte con su discreción que la ociosidad le inoportuna. No hace falta ensañarse en el comportamiento de tan admirable anfitrión con su amable hospitalidad a sus improvisados invitados. Es un rico labriego que no invierte su tiempo en trabajo efectivo. Don Diego vive con cierta holgura pero se desconoce cuál es su ocupación habitual. La crítica social cervantina realizada a este personaje -como a otros de nobles jerarquías- no radica en estar en contra, sino más bien en su actitud vital que muestra la ociosidad que desmorona económicamente a un país que pretendía mantener un imperio. 
La actitud de don Quijote no deja de ser reflejo de una visión irónica de la realidad al estilo de la moria erasmiana con la crítica que hace del comportamiento humano. Erasmo había analizado el origen y los principios de la estulticia. Cómo influía en las edades, las ocupaciones, los estados y las profesiones del hombre, sin olvidar ningún estrato social: ' ... no podréis encontrar empresa ilustre alguna sin mi impulso, ni nobles artes que yo no haya inventado' (1976: 49), así pues, la moria erasmiana planeaba sobre la humanidad porque 'la vida humana no es sino una especie de juego de despropósitos’ (1976: 55). Seguramente la base de la ironía cervantina radica en este planteamiento que no solo alcanza la locura del protagonista, sino también a muchos de los otros personajes que evidencian actuaciones poco razonables $\mathrm{y}$ atuendos extravagantes.

\section{LOS DUQUES O LA OCIOSIDAD POR OCUPACIÓN}

El episodio de los duques es uno de los más extensos de la obra (II, 30-57 y 69-70). La mansión que acoge estas aventuras es uno de los espacios que recibe más denominaciones: 'casa de placer, castillo, palacio, fortaleza o casa de campo’ (Allen editor, II, 30, 254 nota) y cuyos dueños nunca tienen más identidad que la del título que ostentan: duque y duquesa. La identificación con los duques Luna y Villahermosa no tiene mayor relevancia que la coincidencia del nombre del Caballero del Verde Gabán con aquel otro que vivió en la vivienda del barrio del Rastro de los Carneros de Valladolid. Tampoco este castillo se le sitúa geográficamente más allá de que está 'camino de Zaragoza'. En ese entorno aparece el primer grupo de personajes que ha leído la Primera parte de las aventuras del hidalgo y se aprovecha de saber quiénes son don Quijote y Sancho Panza. Durante estas jornadas Sancho logrará su objetivo tan ansiado: ser gobernador de una ínsula. Por primera vez amo y escudero aparecerán de forma separada, ya sea para hablar con el duque o la duquesa con lo cual conocerán el encantamiento de doña Dulcinea en el Toboso y quién ha estado objeto de esa sofisticada treta; o ya sea para que Sancho desempeñe su cargo de gobernador. Nada se escapa a la creación y recreación de este universo para que el nombre de Barataria sea objeto de la ironía cervantina: porque el lugar se llamaba 'Baratorio, o ya por el barato con que se le había dado el gobierno.' (II, 45, 888). El término 'barato’ implica varios significados: propina, engaño o el más actual de valor rebajado o de bajo coste. El lector, así pues, tiene dónde escoger el origen del nombre de esta ínsula que está tan alejada del mar.

Antes de partir, don Quijote aleccionará a su escudero del que lamentará que no sepa leer y escribir (II, 43), pero está convencido que tiene 'buen natural' (II, 43, 876) que le permitirá salir airoso. Sancho será parco en el comer y en el dormir porque el médico de su séquito apenas le deja probar bocado o descansar con reposo. El agobio que le acaban creando sus súbditos 
provocará que Sancho admita: 'Yo no nací para ser gobernador' (II, 53, 957) pero ello no ha impedido que el escudero haya superado con creces su ejercicio del poder con justicia y equidad. En este sentido Sancho no olvida uno de los preceptos que le diera su amo: 'cuando la justicia estuviese en duda, me decantase y acogiese a la misericordia' (II, 51, 940).

No es casual la caída en la sima, tras abandonar su gobierno que equivaldría al descenso a la Cueva de Montesinos de don Quijote. Allí se confirma el encantamiento de su amada, aquí Sancho muestra cómo ha salido de su gobierno: 'muerto de hambre, descolorido, y sin blanca' (II, 55, 972). No ha sacado beneficio alguno que es la máxima que se desprende de su intrépida aventura, mientras los duques no se arrepienten de sus burlas (II, 56).

Es curioso que aunque los duques les crean pseudoaventuras como salir de caza para la cual don Quijote es obsequiado con un vestido de monte que no acepta, porque su ocupación: '[el] duro ejercicio de las armas' (II, 34, 814) no le permite tantos atuendos; la visita del sabio Merlín que determina que si Sancho cumple con los azotes impuestos no solo desencantará a doña Dulcinea sino que además logrará el gobierno de una ínsula; el periplo a las altas esferas a lomos de Clavileño; la batalla aplazada con el lacayo Tosilos y el enamoramiento desenvuelto y atrevido de Altisidora, pero don Quijote lamenta esta vida ociosa, pues él no nació para la inactividad (II, 51). Es la segunda vez que se incrimina este estado. La primera había sido en casa de don Diego de Miranda. En todo caso lo que está delatando es la vida ociosa que llevan sus moradores.

Sorprende que los duques, durante toda la estancia de amo y escudero, solo estén preocupados y ocupados en las tretas y burlas de que son objeto sus huéspedes. Tampoco sabemos si el viaje, que había ocasionado el regreso al hogar del caballero del Verde Gabán, tenía algún objetivo ligado con su hacienda. Los poderosos - como, después, Antonio Moreno en Barcelona- no ejercen ninguna actividad profesional. Podría decirse que sus ocupaciones quedan limitadas al ocio o alguna pequeña obligación que se desprende de su condición: escuchar misa -como don Diego Miranda- (también con mucho fervor la escuchaba el escudero arruinado del Lazarillo que estaba preocupado por si eran limpias las manos que amasaron el pan) u organizar a su séquito, en este caso, para realizar las burlas más sofisticadas.

El Duque pese a creer que domina todas las situaciones no logra controlar todos sus planes. Sancho, con acertada discreción, decide abandonar su gobierno antes de lo programado; don Quijote empieza a añorarse de lo que da sentido verdadero a su vida que no es precisamente la vida regalada. Aunque se enfrenta en una batalla aplazada y preparada con todo lujo de detalles en la plaza del castillo con el patíbulo, sus jueces, y el maese de campo que sitúa a los contendientes, el lacayo Tosilos se da por vencido en mitad de la contienda, provocando la extrañeza de doña Rodríguez y su hija cuando éste descubra su rostro. Ellas comprueban que no era el verdadero esposo -que hacía tiempo, después de haber burlado a la doncella, había huido- sino el lacayo del Duque. No pensaba el Duque reclamarle su obligación al verdadero 
ofensor de la hija de la dueña, pues le debía dinero a su padre que: 'le sal[ía] fiador de sus trampas' (II, 48, 915) y le es más fácil hacer oídos sordos a las súplicas de la dueña Rodríguez. Si en la boda del rico Camacho, cuando Basilio se levanta los presentes corean: ‘Milagro!, ¡Milagro!', y él replica: ‘¡Industria!, ¡Industria!', aquí la dueña y su hija exclaman: ¡Engaño!, ¡Engaño!' que coincide con el que amo y escudero habían detectado cuando las dueñas se hacían pasar por lacayos o cuando amo y escudero dudaban de la veracidad del viaje a las altas esferas.

Si entonces, don Quijote y Sancho justificaron la situación, creyendo que eran los encantadores que los perseguían y que trucaban los seres que se encontraban, el Duque no se queda tan conforme porque sabe el origen de la treta y encierra a Tosilos para comprobar si en plazo razonable vuelve a su prístina figura de esposo burlador. Finalmente acaba dando al traste a sus pretensiones cuando la hija de la dueña lo acepta por esposo, pues vale más lacayo por esposo que no caballero que no lo fue porque la burló y abandonó. Como en el Quijote todo tiene una doble visión, don Quijote y Sancho se encontrarán al lacayo Tosilos que les explicará en qué consistió la burla del Duque y cómo después de su partida fue castigado con cien azotes y la hija de la dueña recluida en un convento y doña Rodríguez marchó a Castilla (II, 66). La resolución del caso recuerda la historia de Andresillo (I, 4 y 31), el mozo que perdía las ovejas y el cruel comportamiento del dueño, con lo cual se manifiesta una vez más la prepotencia del que ostenta el poder.

La actuación del Duque y la Duquesa demuestra que este grupo social, que no se preocupa por las necesidades más elementales porque no pasa hambre, no tiene más pretensiones que la diversión y además cómo actúan cuando no se salen con la suya. Ante esta jocosa situación, se hace inevitable aquella imagen de la moria erasmiana que invertía su tiempo en las actividades más fútiles, en las que como aquí el burlador podía acabar convirtiéndose en burlado como es la resolución de la batalla de Tosilos. El deleite supremo de la estulticia es disfrutar de la insensatez ajena (1976: 55). Además el comportamiento del Duque no parece más noble que el del rico Haldudo que maltrataba a su criado, Andrés. El disfraz y la burla parecen estar en sintonía con el mensaje de la moria erasmiana antes citada. La ociosidad es la crítica más reiterada en todos esos casos: ricos que solo se ocupan de su propia diversión antes que de un comportamiento activo - como el de don Quijote - en una tarea productiva, aunque el protagonista cervantino solo encarne un ideal utópico.

\section{ROQUE GUINART REAFIRMA EL IDEARIO DE DON QUIJOTE}

Antes de llegar a Barcelona, don Quijote y Sancho Panza se encontrarán a Roque Guinart quien les acompañará hasta las mismas puertas de la ciudad y les facilitará un salvoconducto para que en la ciudad sean alojados por un amigo suyo: Antonio Moreno. La aparición de un personaje histórico, famoso 
por sus intrépidas aventuras y su gallardía siempre ha llamado la atención de la crítica (Riquer, Martínez-López, Aladro Font, García Santo-Tomás y Zimic). Roque Guinart era una adaptación del verdadero Perot Rocaguinarda que había nacido en Oristà en 1582. No parece verosímil que Cervantes conociese al famoso bandolero, pero sabía de sus aventuras cuando se cree fue a la ciudad condal en 1610, para entrevistarse con su protector, el conde de Lemos, que también lo acabó siendo de Guinart, pues fue virrey de Nápoles. Roque Guinart, durante la acción de la Segunda parte del Quijote, estaba exiliado desde 1611 en Nápoles donde acabó sus días, si fijamos los hechos, sobre la fecha del 20 de julio de 1614, según la carta de Sancho a su mujer (II, 36). También en su Galatea, Cervantes hace referencia a la existencia de bandoleros catalanes por los que 'manifiesta simpatía y hasta cierta admiración' (Riquer 1989: 59). En el entremés, La cueva de Salamanca, un estudiante que fue asaltado en Cataluña por las tropas de Roque Guinarde (tal como allí es aludido) explica que de haber estado él presente "no consintiera que se me hiciera agravio, porque es muy cortés y comedido, y además limosnero'. ¿Qué relación tuvo con el autor para defender este ideario en diferentes obras? Todavía es una incógnita, pero sí es evidente que la actitud moral de don Quijote está más de acuerdo con la vida liberal y al aire libre del famoso bandolero que con la ociosa y convencional de los personajes poderosos.

La descripción que da el narrador del bandolero en el Quijote no se ajusta a la realidad, pues se parecía más a don Quijote por ser alto, delgado y enjuto (Riquer 1989: 82) que 'robusto [y] de mediana proporción' (II, 60, 1008) como se describe en las páginas de la obra. Que la descripción no concuerde con la realidad no resta credibilidad al relato del Quijote, pues no estamos ante una crónica histórica y la ironía cervantina ha debatido en más de una ocasión esta diferencia entre historia y poesía (II, 3). ¿Qué representa este personaje histórico frente al resto que ha hecho objeto de burla al héroe de la obra? De entrada, Roque Guinart advierte cuál es la enfermedad de don Quijote: 'tocaba más en la locura que en la valentía' (II, 60, 1008), y además recordaba haberle oído nombrar. La obra no aclara, como en el caso de otros personajes, que la haya leído. Don Quijote en seguida da muestras de conocer al bandolero: '¡Oh valeroso Roque, cuya fama no hay límites en la tierra que la encierren! (II, 60, 1008). Es el primer encuentro entre dos personajes famosos: uno histórico y otro literario, pero ello no obliga a que tenga que ajustarse a la realidad histórica. Es más, Cervantes es muy consciente de ello, como lo es del juego literario que le brinda esta nueva posibilidad: que un personaje cuyo estilo de vida admiraba desde hacía tiempo departa con su protagonista que comparte, en el fondo, su idea de la justicia y su actitud ante la defensa de los menesterosos. En la interpretación de este personaje, solo se avanzará, si se llega a conocer qué sabía Cervantes sobre Roque Guinart. Los estudios más recientes sobre Perot Rocaguinarda dejan entrever que Cervantes era conocedor de la realidad catalana en la que personajes como Guinart luchaban contra las injusticias sociales. Situación que Cervantes había planteado en otros episodios del Quijote como la liberación de los condenados a galeras: 
'Frente al cuadro cervantino, la justicia real resulta serlo sólo en el sentido, familiar a los marginados, de ajusticiar o perseguir a los pobres infelices' ${ }^{5}$.

Nada más se han presentado ambos personajes, cuando son abordados por una mujer que viene disfrazada de hombre. No es una historia a la que don Quijote esté deshabituado, pues antes de abandonar el palacio de los duques ha defendido en duelo a la hija de doña Rodríguez. Roque Guinart auxilia a la joven que por celos ha dejado mal herido a un joven que seguramente es del bando contrario a los nyerros, en el que militaba Guinart, por eso la dama da detalles de las familias a las que pertenecen ella y su amado. Es Roque Guinart quien va en busca del herido para que cumpla con su promesa y a quien encuentran casi muerto. Después de explicar el enamorado, Vicente Torrellas, que ha sido un malentendido muere. Este episodio refuerza para Zimic la visión histórica del pasaje dentro de la ficción que lo considera una 'metáfora de una deplorable faceta de la realidad histórica, política, social y moral de la España de los Felipes' (1995: 26). El famoso bandolero, después de la decisión de la dama de ingresar en un convento, promete que defenderá a su familia de cualquier ataque. Tras situaciones que parecían más propias de un enredo amoroso, don Quijote ve de cerca el desenlace que acaba con la muerte de uno de los enamorados. Aunque el episodio de Grisóstomo (I, 14) había supuesto un final trágico, el caballero no había sido -como ahoratestigo directo.

En el camino, don Quijote encuentra tanto al Caballero del Verde Gabán como a Roque Guinart. Si aquel traía un alfanje morisco (II, 16), éste lleva cuatro pistoletes (que en aquella tierra llaman pedreñales) (II, 60). De hecho el Caballero del Verde Gabán lleva el sable de adorno, mientras Roque echa mano de su espada, que no se describe en el relato, para guardar el orden entre su tropa y le abre la cabeza a uno de los miembros que desacataba con unos comentarios sus instrucciones (II, 60). El comportamiento de Guinart está más de acuerdo con lo que Rey Hazas establece para el caudillo de estos bandoleros que se le destaca: 'por su nobleza y móviles honorables, de los demás bandidos.' (1991: 203). Martínez-López incluso ve en esta actitud como en la situación de los moriscos que don Quijote conocerá, en lo que en un principio parecía un paseo a bordo de una galera catalana, la falta de una política que: 'desecha ... soluciones [más] conciliatorias, [y se] opta por las represivas’ (1991: 76).

Roque Guinart reparte entre los suyos el botín con equidad (Lorente-Murphy y Frank) pero también respeta a sus rivales y no los desvalija totalmente. Sin entrar a discutir el tipo de justicia que impone Guinart, sí es remarcable que ambos personajes son justos y equitativos como lo han demostrado en el reparto del botín o en los consejos que don Quijote le dio a Sancho antes de partir a Barataria. Guinart y don Quijote poseen cualidades similares, uno

5. Martínez-López (1991: 75). También está en esta línea el biógrafo más reciente de Rocaguinarda, Xavier Roviró Alemany. 
es: compasivo, bien intencionado, sus enemigos lo consideran cortés y liberal (II, 60); don Quijote afirma que desde que es caballero andante es: 'valiente, liberal, generoso, cortés, etc.' (I, 50, 511) pero Roque Guinart en cambio sabe que su vida es arriesgada -desconfía incluso de sus propios hombres a los que oculta su paradero- porque el virrey ha puesto precio a su cabeza. Es en este aspecto en el que se diferencian, porque aunque don Quijote, después de la liberación de los galeotes se sienta perseguido por la Santa Hermandad, cuando los encuentre en la venta es don Quijote quien sabe poner orden en aquel campo de Agramante: 'A cuya gran voz todos se pararon' (I, 45, 470). $\mathrm{Si}$ estos lo reconocen y reclaman que se cumpla el mandamiento que llevan sobre su persona, don Quijote profiere: ‘QQuién fue el ignorante que firmó mandamiento de prisión contra un caballero como yo soy? ... que ignoró que son esentos de todo fuero judicial los caballeros andantes' (I, 45, 473). La justicia que amparaba a los nobles no impide que don Quijote deje en libertad a personajes no menos rudos, groseros y violentos que los que militan entre las tropas de Roque Guinart que les asaltan en el camino o los que censuran a su capitán. Roque Guinart es el que manda cómo deben hacerse las cosas, lo que recuerda aquel lema que don Quijote profirió ante Andresillo y Haldudo: 'por sus obras los conoceréis' (I, 4, 50).

Cervantes tiene muy claro que un personaje ejemplar como Roque o el propio don Quijote tienen principios morales similares aunque liberen a galeotes que la justicia exigía que cumpliesen una condena que solo don Quijote cuestiona, o como Roque que asalta en los caminos pero sabe hacerlo con compasión como aparece en el Quijote o en La cueva de Salamanca. Los que resultan más penosos y patéticos son aquellos que se burlan del héroe porque saben cuál es su obsesión. Su comportamiento está más cercano al de la moria erasmiana y que de forma sarcástica quedan más en evidencia que don Quijote, objeto de sus burlas.

Con todo eso, a don Quijote que permaneció tres días y tres noches con Roque no le faltó en 'que mirar y admirar en el modo de su vida' (II, 61, 1028). Por primera vez no se aburre de esta convivencia aunque 'estuviera trescientos años' (II, 61, 1028). Roque tiene algo que no tenían sus anfitriones anteriores: acción constante, eso que tanto echa en falta entre los personajes económica y socialmente mejor situados. Sus vidas son demasiado ociosas. Seguramente en este aspecto Cervantes presenta una alternativa, aunque nos lo muestre con un revestimiento poético. La propuesta de don Quijote de restablecer una utopía como la Edad Dorada habría sido más viable, si el país hubiera tenido en mayor estima el trabajo manual como advertía el arbitrista González de Cellorigo (Elliott 1979: 337). La falta de este estímulo entre las clases influyentes no permitió un desarrollo económico más próspero en un país que llenaba sus arcas con metales preciosos procedentes del Nuevo Mundo. En esta misma línea Aladro Font defiende que: 'La exaltación y respeto por la figura del bandolero lleva implícita la condena de la sociedad española del siglo XVI' (1992: 136). En todo caso, no se supo gestionar la demanda de un comercio que abasteciese este nuevo mercado. Elliott analiza esta situación 
en el soneto que Cervantes dedicó al entonces recién desaparecido Felipe $\mathrm{II}^{6}$. Esta 'Máquina Insigne' que era Felipe II cedió a las presiones de la guerra para mantener a raya al turco y a los protestantes pero no logró sus propósitos. $\mathrm{Si}$ las exequias recordaban la gloria pasada, no podían borrar las penurias que se habían vivido para intentar erigirse como bastión del cristianismo (2004: 45).

La ironía cervantina presenta al lector un ideario alternativo a la mentalidad dominante de un país exhausto tras sucesivas bancarrotas, pero en manos de don Quijote y Roque Guinart, uno un loco y el otro un personaje marginal, aunque de origen noble, las soluciones parecen poco viables. Esta demoledora crítica social solo podía presentarse en clave de humor. Su planteamiento solo puede representar una utopía, pero en boca de dos seres que tenían una cierta aceptación, parece todavía más irónico. El primero, famoso por sus aventuras como caballero andante, pero poco se había entendido su mensaje si consideramos la Segunda parte apócrifa que solo se quedó con el mensaje humorístico de la actuación del héroe. El segundo, aunque había gozado de cierta popularidad en tierras catalanas, finalizó sus días en Nápoles que en aquel entonces, como Flandes, eran destinos para forajidos. Si Cervantes estaba bien informado, sobre las aventuras de Roque Guinart, debía conocer que ya no estaba en las proximidades de Barcelona cuando él pretende situarlo en su obra, por lo tanto este 'historiador moderno' presenta un planteamiento utópico. Incluso Barcelona está en ese núcleo perfecto de la utopía cervantina que por aquel entonces estaba en el polo opuesto de las grandes urbes como Sevilla, centro del comercio del Nuevo Mundo.

\section{BARCELONA: ESPACIO URBANO ENTRE LA FICCIÓN Y LA REALIDAD}

Barcelona es el único núcleo urbano que atraviesa don Quijote en sus aventuras. Llega a la ciudad de madrugada y espera ante sus murallas que amanezca. Sorprende a amo y escudero el mar nunca visto, el ajetreo de la ciudad y las galeras ancladas en el puerto. Si bien es recibido con honores, pues Antonio Moreno lo reconoce sin ser presentado previamente, no se libra de las burlas de los chicos que atan aliagas en las colas de Rocinante y el rucio de Sancho, o de una voz crítica y mordaz de un castellano que, al igual que la del eclesiástico en el palacio de los duques, propone a don Quijote que abandone su vida de caballero andante y se dedique a su hacienda y sus labores domésticas. Si en el campo unos cabreros le ofrecían un puñado de frutos secos que le era suficiente para proferir el discurso de la Edad Dorada, ahora en el entorno urbano la visita a una imprenta le permitirá despertar de nuevo la admiración ajena por sus conocimientos en lengua toscana, en obras de polémica devoción como Luz del 
alma que después volverá a citar indirectamente en su lecho de muerte: 'leyendo otros [libros] que sean luz del alma' (II, 74, 1100) y sobre la que afirma con ironía: 'son menester infinitas luces para tantos desalumbrados' (II, 62, 1033), o la crítica feroz a la Segunda parte del apócrifo Avellaneda que creía quemado (no se olvide la quema de su biblioteca en la Primera parte y la finalidad de eliminar los libros poco adecuados) 'pero su San Martín se le llegará, como a cada puerco' (II, 62, 1033), o su visita a las galeras solicitada por el propio don Quijote, pues aunque estuvieron en barco encantado para socorrer a un supuesto caballero (II, 29), no las habían visto antes como tampoco el mar. La experiencia marina no es una simple visita con la mirada de la admirada contemplación ante lo novedoso. El enfrentamiento entre la galera y el bergantín, cuyos tripulantes acaban dando muerte a dos de los soldados, crea un conflicto poco propio de una visita turística. La llegada del virrey salvará de la muerte segura a Ana Félix que también es reconocida por su padre y este por Sancho. Cervantes plantea la cuestión de la expulsión de los moriscos desde la perspectiva emocional de las familias que quedaron disgregadas y además perdieron su identidad. MartínezLópez ve en este episodio un ejemplo de la 'contienda fratricida' que dividió 'la cristiandad española vieja de la de origen morisco' (1991: 69).

La actuación de Antonio Moreno y su mujer, quizás menos diabólica que la duquesa, con la cabeza encantada y el baile improvisado después de la cena, no parece muy diferente a la de los duques. Barcelona aparece mucho más identificable que el lugar de la Mancha de cuyo nombre no quiere acordarse el narrador al inicio de la obra, pero tampoco aquí habrá más identificaciones urbanas cuando don Quijote deambule por sus calles. Ni la palaya, en la que se enfrente con el caballero de la Blanca Luna, tiene una localización precisa. Eso sí, ahora se comprobará la identidad de este sorprendente Caballero de la Blanca Luna (II, 65) para saber si se trata de una broma pesada y quien encargará esta indagación será el propio virrey que apenas ha visto actuar al caballero manchego (II, 64). Canavaggio (2007: 58) ha destacado que este detalle, de situar la derrota o el hecho de ser vencido -como prefiere Carme Riera ${ }^{7}$ - en un núcleo urbano como Barcelona y ante autoridades, lo convierte en mucho más trascendental que haberlo vencido antes don Quijote en los campos de Montiel $^{8}$. Un entorno urbano quizás más propio de la novela picaresca certifica el final del protagonista que ha sido planeado cuando cambió el destino de su héroe. Episodio que entre los ilustradores del Quijote ha despertado un interés continuo, pero con escasas variaciones desde los finos grabados de Vanderbank en 1738 hasta la primera edición crítica de Tomàs Gorchs $(1859)^{9}$.

7. Riera (2005: 33-43). Trabajo que además propone una nueva fecha para la estancia de Cervantes en Barcelona en 1571 con motivo de los preparativos de la batalla de Lepanto.

8. Canavaggio (2007: 49-58).

9. Roger Miralles, Isabel Maria (3 noviembre 2015). "Barcelona en les il·lustracions del Quixot.", en http://www.bnc.cat/El-Blog-de-la-BC/Barcelona-en-les-il-lustracions-del-Quixot\#comments. También en este trabajo se establece la relación de la Edad Dorada con el entorno urbano y la aparición de Roque Guinart. 
El elogio de la ciudad condal: 'archivo de la cortesía, albergue de los extranjeros, hospital de los pobres, patria de los valientes, venganza de los ofendidos y correspondencia grata de firmes amistades, y en sitio y en belleza, única' (II, 72, 1091) que está situado después de abandonarla, es un broche final a esta teoría que héroe y bandolero discuten sobre los aprietos que le causó la venganza de un agravio a la que se sumaron otras ajenas. Don Quijote le brinda su ayuda: 'yo le enseñaré a ser caballero andante [que] en dos paletas le pondrán en el cielo’ (II, 60, 1014-15). Roque Guinart sonríe ante tal consejo, como el lector. Aunque es ingenua su oferta, parece una razón para combatir tanto desastre consecutivo en la historia del país. Si bien ambos no están conformes con las instituciones, está claro que están en dos planos diferentes Roque Guinart era un personaje histórico que ya no estaba en Cataluña (historia), don Quijote uno de ficción (poesía) que representaba un ideal utópico. Una vez más se diluye esa frontera que parecía tan clara entre historia y poesía. El punto de enlace entre ambos personajes es: 'la aspiración de regreso a una naturaleza ideal, a un mundo de libertad' (Jauralde 1991: 252). Sin lugar a dudas, la coincidencia - dentro de la ficción - del ideario de don Quijote con el de Roque Guinart - personaje real - afianza la visión que tiene el caballero manchego de su creencia en un mundo más idílico como el de la Edad Dorada y además refuerza su final como caballero andante en un entorno real. Llegados a este punto la realidad y la ficción son difíciles de deslindar porque ¿dónde empieza una y acaba la otra? En todo caso, Cervantes plantea esta utopía de la Edad Dorada desde la vertiente de la historia y la ficción que aunque no puede remediar un panorama social tan complejo, sí literariamente ofrecer una alternativa. Alternativa que por otra parte no parece tener pretensiones moralizantes, sino más bien sugerir una visión irónica del desencanto de unos ideales en crisis.

\section{BIBLIOGRAFÍA CITADA}

Aladro Font, Jorge (1992). «Entre Roque Guinart y Don Quijote, o el desdoblamiento de Cervantes», Anales Cervantinos. XXX, pp. 129-137.

Allen, John Jay (ed.) (1997). El Ingenioso Hidalgo Don Quijote de la Mancha. Madrid: Cátedra.

Bataillon, Marcel (1979). Erasmo y España. Madrid: Fondo de Cultura Económica.

Blasco, Javier (2006). «Notas para la historia de una falsificación: el Quijote de Avellaneda», en 4 siglos os contemplan: Cervantes y el Quijote. Madrid: Eneida, pp. 11-21.

Canavaggio, Jean (1987). Cervantes. Madrid: Espasa-Calpe.

Canavaggio, Jean (2007). «Cervantes y Barcelona», en Cervantes, el Quijote y Barcelona. Barcelona: Fundació Caixa de Catalunya/Universitat Autónoma de Barcelona, pp. 49-58.

Castro, Américo (1960). «Los prólogos al Quijote», en Hacia Cervantes. Madrid: Taurus, pp. 231-266.

Castro, Américo (1971). «Cómo veo ahora el Quijote», en El Ingenioso Hidalgo Don Quijote de la Mancha. Madrid: Magisterio Español, pp. 9-102. 
Castro, Américo (1972). El pensamiento de Cervantes. Barcelona: Noguer, 2a edición ampliada y con notas de Julio Rodríguez Puértolas.

Cervantes, Miguel de (2012). El Ingenioso Hidalgo Don Quijote de la Mancha. Francisco Rico (ed.). Madrid: Santillana.

Close, Anthony J. (2005). La Concepción romántica del 'Quijote'. Gonzalo G. Djembé (trad.). Barcelona: Crítica.

Elliott, John H. (1979). La España Imperial, 1469-1716. Barcelona: Vicens Vives.

Elliott, John H. (2004). «'Máquina insigne’: La monarquía hispana en el reinado de Felipe II», en España en tiempos del Quijote. Madrid: Taurus, pp. 41-60.

Erasmo de Rotterdam, Desiderio (1976). Elogio de la locura. Madrid: Espasa-Calpe.

García Santo-Tomás, Enrique (1993). «Aventura fingida y aventura verdadera: Roque Guinart frente a don Quijote», Anales Cervantinos. XXXI, pp. 215-228.

Gómez Canseco, Luis (2006). «Don Quijote Avellanizado y Desavellanizado», en 4 siglos os contemplan: Cervantes y el Quijote. Madrid: Eneida, pp. 39-48.

Jauralde Pou, Pablo (1991). «Coloquio, El bandolero: aspectos literarios», en Le bandit et son image au siècle d'or. Madrid: Casa Velázquez/Publicacions de la Sorbonne, pp. 250-252.

Lapesa, Rafael (1971). "Góngora y Cervantes: Coincidencias de temas y contrastes de actitudes», en De la Edad Media a nuestros días. Madrid: Gredos, pp. 219:241.

Lorente-Murphy, Silvia y Roslyn M. Frank (1982). «Roque Guinart y la justicia distributiva en el Quijote», Anales Cervantinos. XX, pp. 103-113.

Maldonado Palmero, Gabriel (2004). Quién es quién en el Quijote y en el Quijote de Avellaneda., Madrid: Acento.

Martínez-López, Enrique (1991). «Sobre la amnistía de Roque Guinart: El laberinto de la bandositat catalana y los moriscos en el Quijote», Cervantes XI [2], pp. 69-85.

Márquez Villanueva, Francisco (2011). Personajes y fuentes en el 'Quijote'. Barcelona: Bellaterra.

Rey Hazas, Antonio (1991). «El Bandolero en la novela del Siglo de Oro», en Le bandit et son image au siècle d'or. Madrid: Casa Velázquez/Publicacions de la Sorbonne, pp. 201-215.

Rey Hazas, Antonio (2011). Introducción. Quijote de Cervantes. Madrid: Alianza, pp. I-LII.

Rico, Francisco (ed.) (2012). El Ingenioso Hidalgo Don Quijote de la Mancha. Madrid: Santillana.

Riera, Carme (2005). «Cervantes, el Quijote y Barcelona (Hipótesis de una estancia barcelonesa de Cervantes en 1571)», Anales Cervantinos. XXXVII, pp. 33-43.

Riquer, Martín de (1989). Cervantes en Barcelona. Barcelona: Sirmio.

Roger Miralles, Isabel Maria (3 noviembre 2015). "Barcelona en les il·lustracions del Quixot", en http://www.bnc.cat/El-Blog-de-la-BC/Barcelona-en-les-il-lustracions-delQuixot\#comments.

Roviró i Alemnay, Xavier (2006). Perot Rocaguinarda, cap de bandolers. Barcelona: Farell.

Vilanova, Antonio (1989). Erasmo y Cervantes. Barcelona: Lumen.

Zimic, Stanislav (1995). «Del tálamo al túmulo: Clara Jerónima, Vicente Torrellas y Roque Guinart», Verba hispanica: Anuario del Departamento de la Lengua y Literatura Españolas de la Facultad de Filosofía y Letras de la Universidad de Ljubljana. 5, pp. 11-26.

Recibido: 17 de abril de 2016

Aceptado: 27 de junio de 2016 